\title{
Ivermectin Resistant and Susceptible Third-stage Larvae of Haemonchus contortus: Cholinesterase and Phosphatase Activities
}

\author{
Consuelo Giménez-Pardo/+ , Maria Mercedes Martínez-Grueiro*, Alicia Gómez-Barrio*, \\ Filomena Rodríguez-Caabeiro
}

Departamento de Microbiología y Parasitología, Facultad de Farmacia, Universidad de Alcalá, Crtra. Madrid-Barcelona km 33, 28871 Alcalá de Henares, Madrid, España *Departamento de Parasitología, Facultad de Farmacia, Universidad Complutense, 28040 Madrid, España

Cholinesterase and acid phosphatase (AP), but not alkaline phosphatase activities, were detected in cytosolic and membrane-bound fractions of ivermectin resistant and susceptible Haemonchus contortus infective-stage larvae. Some differences in acetylcholinesterase activity of cytosolic fractions and in the AP activity of these fractions as well as in the response to AP inhibitors by membrane-bound fractions were detected. Data are discussed.

Key words: Haemonchus contortus - cholinesterase - phosphatase - ivermectin - resistant

It is known that parasite enzymatic activities are very variable among different species, sexes, and developmental stages of the biological cycle of the nematodes (Sanderson \& Ogilvie 1971, Rhoads 1981, Lawrence \& Pritchard 1993, Alonso-Villalobos \& Martínez-Grueiro 2000, GiménezPardo et al. 2003). Recent studies have also revealed differences among isolates resistant and susceptible to several antihelmintics i.e. morantel tartrate (Sutherland 1987), ivermectin (Echevarría et al. 1992) benzimidazoles (Sutherland \& Lee 1993) or more recently to levamisole (Giménez-Pardo et al. 2003).

Some authors have suggested that after treatment with some antihelmintics, nematodes have a reduced metabolism which may have an effect on production of enzymatic activity by these nematodes (Sharpe \& Lee 1981). Others have observed differences in propionyl esterases between ivermectin-resistant (IVM-R) and ivermectin-susceptible (IVM-S) strains of Haemonchus contortus (Echevarría et al. 1992). In the present paper we have studied the possibility that hydrolases, like cholinesterases and phosphatases, that play important biological roles (Massoulié et al. 1993, Selkirk et al. 2001, Martínez-Grueiro 2002) would also express differences in an IVM-R isolate and an IVM-S isolate of $H$. contortus $\mathrm{L}_{3}$ larvae.

Both IVM-R and IVM-S isolates of $H$. contortus were obtained as frozen samples from the Institute for Animal Science and Health (ID-DLO), Lelystad, The Netherlands. The organization which supplied the nematode periodi-

\footnotetext{
${ }^{+}$Corresponding author. Fax: +34-1-885.4663. E-mail: consuelo.gimenez@uah.es

Received 24 June 2003

Accepted 11 February 2004
}

cally checked the strains for susceptibility or resistance to ivermectin. After thawing, the helminths were resuspended in an $10 \mathrm{mM}$ Tris-HCl buffer $\mathrm{pH} 7.2$, with penicillin (1 mg/ml) and dehydrostreptomycin sulphate $(2 \mathrm{mg} / \mathrm{ml})$, homogenized in a glass Potter-Elvejem homogenizer and samples ultracentrifugued at 100,000 $\mathrm{x}$ g in a Beckman XL100 ultracentrifugue for $30 \mathrm{~min}$ at $4^{\circ} \mathrm{C}$. Supernatants were centrifuged under the same conditions: this second supernatant was kept as the cytosolic fraction. To obtain the membrane-bound fraction, homogenates were prepared as mentioned above, and the pellet was suspended in a $1 \mathrm{ml}$ of $10 \mathrm{mM}$ sodium citrate buffer $\mathrm{pH} 6.5$ containing $1 \mathrm{ml}$ of 0.2 (v/v) Triton X-100 for $3 \mathrm{~h}$ with frequent stirring on a vortex (Heidolph, Reax Top) for $1 \mathrm{~min}$ every $30 \mathrm{~min}$. Each Triton extract was then centrifuged as before. The supernatant was saved and the pellet was extracted again for an additional $3 \mathrm{~h}$. The Triton X-100 supernatants were pooled as the membrane-bound fractions. When required, Triton X-100 was removed from the preparations by the addition of $0.3 \mathrm{~g} \mathrm{SM}-2$ Bio Beads (Bio Rad) per mililiter of the preparation and shaking gently for $2 \mathrm{~h}$ at $4^{\circ} \mathrm{C}$ (Chang \& Opperman 1991). Finally, samples were aliquoted and conserved at $-80^{\circ} \mathrm{C}$ until use.

Protein amounts of the cytosolic fractions was 1.47 $\mathrm{mg} / \mathrm{ml}$ for the IVM-R isolate and $1.37 \mathrm{mg} / \mathrm{ml}$ for the IVM-S isolate as determined by the Bradford method (Bradford 1976). Due to the potential interaction of the Coomasie contained in Bradford reactive with the detergent (Kirazov et al. 1993), protein amounts for the membrane-bound fractions were determined by the Peterson method (Peterson 1983 ), and was found to be $2.28 \mathrm{mg} / \mathrm{ml}$ for the IVM-R isolate and $2.31 \mathrm{mg} / \mathrm{ml}$ for the IVM-S isolate.

Cholinesterase (ChE) activity and phosphate activities were determined by a modified Ellman test (Ellman et al. 1961, Rathaur et al. 1987) and Moulay and Robert-Gero (1995) method, respectively. Quantification of the ChE activity was performed using acetylthiocholine iodide 
(ATCI) as substrate. The increases in OD were converted to units per litre. One unit was the equivalent to $1 \mathrm{nmol}$ of substrate hydrolized per min per $\mathrm{mg}$ of protein and results are expressed as the mean \pm standard error of three independant determinations. In the inhibition assays (20 $\mu \mathrm{l}$-samples of cytosolic or membrane-bound fraction) plus $5 \mu \mathrm{l}$ of each inhibitor were first incubated at $22^{\circ} \mathrm{C}$ for 10 min before measuring the increase in OD. The final concentrations and inhibitors used were: $500 \mathrm{nM}, 25 \mathrm{nM}$, and $1 \mathrm{nM}$ of 1,5-bis(4-allyl(dimethyammonium phenyl)pentan 3 one dibromide) (BW2845C51) and $30 \mathrm{mM}, 10 \mathrm{mM}$ and 1 $\mathrm{mM}$ of tetraisopropyl pyrophosphoramide (iso-OMPA). Quantification of the phosphatase activity of cytosolic and membrane-bound fractions was performed using 10 $\mathrm{mM}$ p-nitrophenyl phosphate (pNPP) (Sigma, St. Louis, MO, US) as substrate and the reaction product was measured at $405 \mathrm{~nm}$, using an Ultrospec III Spectrophotometer (Pharmacia, LKB). One unit of specific activity was defined as $1 \mu \mathrm{mol}$ of p-nitrophenol hydrolized per hour per $\mathrm{mg}$ of protein under assay conditions (Giménez-Pardo et al. 2003). Determinations were carried out with $50 \mathrm{mM}$ sodium acetate buffer at several $\mathrm{pH}$ values (3.5-6.0), 50 $\mathrm{mM}$ Tris- $\mathrm{HCl}(\mathrm{pH} 7.0-9.0)$ and $50 \mathrm{mM}$ diethanolamine $(\mathrm{pH}$ 10.0-11.5). Phosphatase from different samples was also assayed in the presence of several phosphatase inhibitors to their optimum $\mathrm{pH}$ values. Inhibitors and their final concentrations were: $10 \mathrm{mM}$ and $1 \mathrm{mM}$ of $\mathrm{L}(+)$ tartaric acid, $1 \mathrm{mM} \mathrm{NaF}, 10 \mathrm{mM}$ ethylenediaminetetraacetic acid (EDTA), $10 \mathrm{mM}$ monobasic potassium phosphate, $10 \mathrm{mM}$ levamisole, $10 \mu \mathrm{M}$ okadaic acid and $100 \mu \mathrm{M}$ sodium orthovanadate. Inhibitors were preincubated with the samples in the reaction buffer at $22^{\circ} \mathrm{C}$ for $10 \mathrm{~min}$ before the addition of the substrate. Appropriate media and reagent blanks were run in parallel and test values corrected using these blanks.

Cytosolic ChE activity was six times higher in the IVM$\mathrm{R}$ isolate $\left(12.3 \pm 0.7 \mathrm{nmol} \mathrm{min}{ }^{-1} \mathrm{mg}^{-1}\right)$ than in the IVM-S isolate $\left(2.0 \pm 0.1 \mathrm{nmol} \mathrm{min}^{-1} \mathrm{mg}^{-1}\right)$. Although this difference was very notable, we have previously detected in other $H$. contortus isolates (susceptible and resistant to levamisole) (Giménez-Pardo et al. 2003) a ChE activity similar to the detected activity in the IVM-R isolate analyzed in this study. If the difference now observed is real or not requires further studies. As in benzimidazole-resistant and susceptible isolates (Sutherland \& Lee 1993), the raised levels of $\mathrm{ChE}$ of the resistant isolate could be related to antihelmintic resistance. Krause et al. (1998) suggested that ivermectin could act as a positive allosteric effector of the alpha7 neuronal nicotinic acetylcholine receptor.

Values of $23.3 \pm 4.0 \mathrm{nmol} \mathrm{min}{ }^{-1} \mathrm{mg}^{-1}$ for the IVM-R isolate and $20.4 \pm 3.5 \mathrm{nmol} \mathrm{min}^{-1} \mathrm{mg}^{-1}$ for the IVM-S isolate were obtained in the membrane-bound fractions after the detergent was removed (Tarrab-Hazdai et al. 1984). It is also remarkable that in the membrane-bound fractions, activities were very similar to that previously reported (Giménez-Pardo et al. 2003).

ChE may also be distinguished by their affinity for, or reactivity with various selective inhibitors: BW284C51 for acetylcholinesterases and iso-OMPA for pseudocholinesterases. Results have revealed that enzymatic activity is a "true" acetylcholinesterase in both IVM-R and
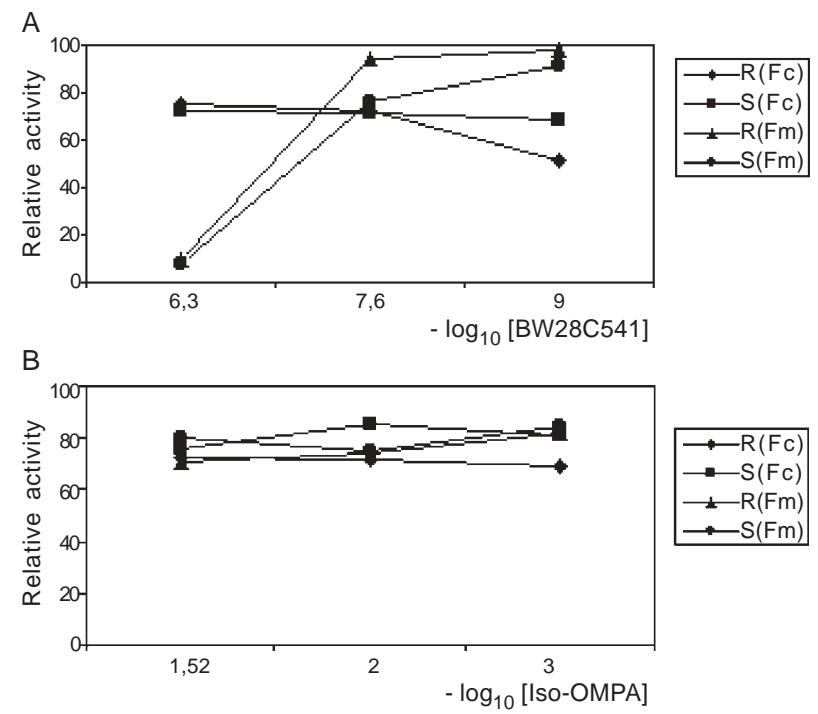

Fig. 1: inhibition of cholinesterase activity in cytosolic $(\mathrm{Fc})$ and membrane-bound (Fm) fractions of ivermectin-resistant (R) and susceptible (S) Haemonchus contortus $\mathrm{L}_{3}$ by BW284C51 (A) and Iso-OMPA (B). Assays were performed in triplicate and standard errors $(<10 \%)$ are omitted.

IVM-S isolates as both were only inhibited by the specific acetylcholinesterase inhibitor BW284C51 at the highest concentration (Fig. 1 A, B).

Phosphatase activity was measured in cytosolic and membrane-bound fractions of both IVM-R and IVM-S isolates by hydrolisis of p-nitrophenylphosphate (pNPP) at several $\mathrm{pH}$ values (3.5-12.0). Acid phosphatase (AP) activity was detected in both isolates in the cytosolic and the membrane-bound fractions, but there was no evidence of any significative alkaline phosphatase activity in any sample. Added magnesium ions $(1 \mathrm{mM})$ had no effect on the phosphatase activity at any $\mathrm{pH}$ value tested. Optimum $\mathrm{pH}$ of 5.0 for cytosolic and 4.5 for membrane-bound fractions both from IVM-R and IVM-S isolates were obtained, after Triton X-100 treatment and Bio Beads extraction. The optimum $\mathrm{pH}$ for each fraction falls inside the usual $\mathrm{pH}$ range of AP of parasitic helminths 3.0-6.0 (Maki $\&$ Yanigasawa 1980). AP activity in cytosolic fractions were 3.5 times higher in the IVM-S isolate $(50.5 \mathrm{U})$ as compared to IVM-R isolate (14.9 U). By contrast, specific activity of the membrane-bound fractions was similar in both isolates (30.4 U for the IVM-R isolate and $34.5 \mathrm{U}$ for the IVM-S isolate). Differences observed between cytosolic fractions are remarkable. If we compare this data with those obtained for $\mathrm{L}_{3}$ susceptible and resistant to levamisole (Giménez-Pardo et al. 2003), we observe that AP activity in IVM-R isolate is the lowest.

As can be seen in Fig. 2 A, B, AP activity was also characterized with several potential inhibitors. It is well known that $\mathrm{AP}$ are inhibited by tartaric acid, $\mathrm{NaF}$ or vanadium (Beh et al. 1991). In cytosolic fractions there was no differences between the IVM-R and the IVM-S isolates and the order of potency was vanadium $>$ tartaric acid $>$ $\mathrm{NaF}$. Little if any effect was observed with EDTA or 


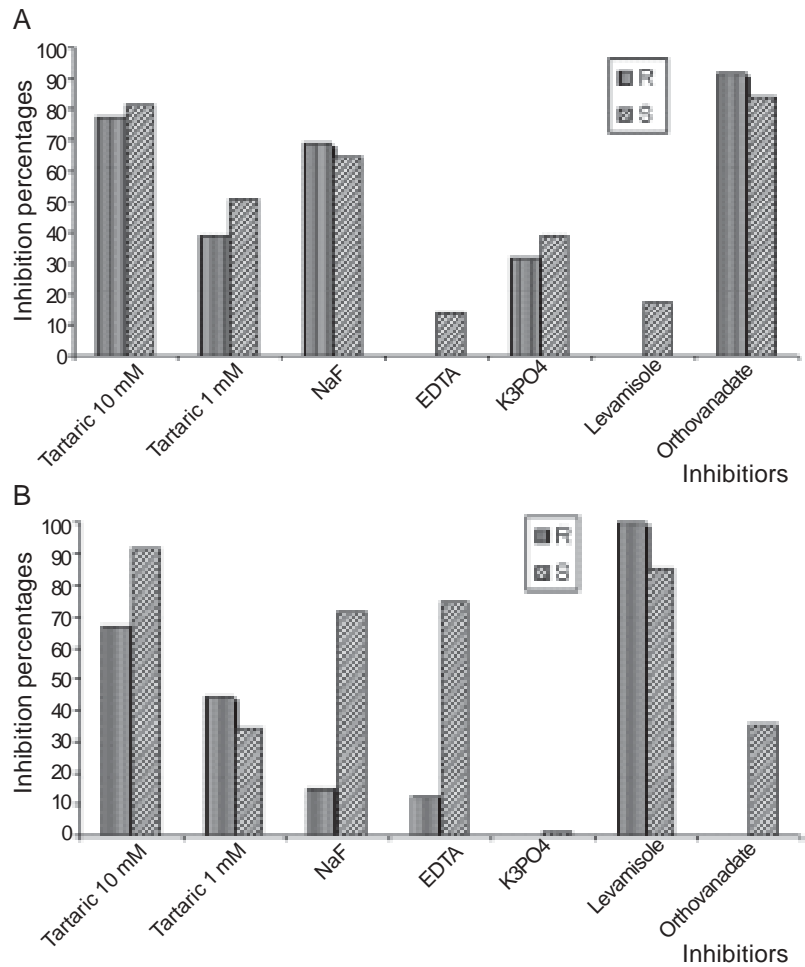

Fig. 2: effect of various potential inhibitors of acid phosphatase activity of cytosolic (A) and membrane-bound (B) fractions of ivermectin susceptible (S) and resistant (R) Haemonchus contortus $\mathrm{L}_{3}$. Assays were performed in triplicate and standard errors $(<10 \%)$ are omitted.

levamisole. These observations indicate that the phosphatase activity detected corresponds to an AP.

However, in the membrane-bound fractions there was differences between both isolates. In fact, the IVM-S isolate was more sensitive than the IVM-R to tartaric acid (91.9\% vs $66.9 \%), \mathrm{NaF}(71.5 \%$ vs $14.8 \%)$, and sodium orthovanadate ( $35.7 \%$ vs $0 \%)$, a specific tyrosine phosphatase inhibitor (Fischer et al. 1991). None of the fractions analyzed (cytosolic or membrane-bound) were affected by $10 \mu \mathrm{M}$ okadaic acid, an inhibitor of serin/ threonin phosphatases (data not shown).

In conclusion, enzymatic activity is altered from some way in IVM-R or IVM-S isolates. However this study has been performed only on two strains, an isolate of both resistant and susceptible to ivermectin, that corresponds to an isolated geographical region. We need obviously to examinate further isolates from many different geographical regions to provide a better understanding of this fact. Experiments are now in progress.

\section{REFERENCES}

Alonso-Villalobos P, Martínez-Grueiro MM 2000. The in vitro secretion of acetylcholinesterase by adult stages of $\mathrm{He}$ ligmosomoides polygyrus: the effects of broad-spectrum anthelmintics. J Vet Med B Infect Dis Vet Public Health 47: $1-8$

Beh CT, Ferrari DC, Chung MA, McGhee JD 1991. An acid phosphatase as a biochemical marker for intestinal development in the nematode Caenorhabditis elegans. Dev Biol 147: 133-143.

Bradford M 1976. A rapid and sensitive method for the quantitation of microgram of protein-dye binding. Anal Biochem 72: $248-254$.

Chang S, Opperman ChH 1991. Characterization of acetylcholinesterase molecular frorms of the root-knot nematode, Meloidogyne. Mol Biochem Parasitol 49: 205-214.

Echevarría FA, Gennari SM, Tait A 1992. Isoenzyme analysis of Haemonchus contortus resistant or susceptible to ivermectin. Vet Parasitol 44: 87-95.

Ellman GLM, Courtny KD, Featherstone RM 1961. A new and rapid colorimetric determination of acetylcholinesterase activity. Biochem Pharmacol 7: 88-95.

Fischer EH, Charbonneau H, Tonks NK 1991. Protein tyrosine phosphatases: a diverse family of intracellular and transmembrane enzymes. Science 253: 401-406.

Giménez-Pardo C, Martínez-Grueiro MM, Gómez-Barrio A, Rodríguez-Caabeiro F 2003. Cholinesterase and phosphatase activities in adults and infective-stage larvae of levamisole resistant and susceptible Haemonchus contortus isolates. Vet Res Comm 27: 611-623.

Kirazov LP, Venkov LG, Kirazov EP 1993. Comparison of the Lowry and the Bradford protein assays as applied for protein stimation of membrane-containing fractions. Anal Biochem 208: 44-48.

Krause RM, Buisson B, Bertrand S, Corringer PJ, Galzi JL, Changeux JP, Bertrand D 1998. Ivermectin: a possible allosteric effector of the alpha 7 neuronal nicotinic acetylcholine receptor. Mol Pharmacol 53: 283-294.

Lawrence CE, Pritchard DI 1993. Differential secretion of acetylcholinesterases and proteases during the development of Heligmosomoides polygyrus. Int J Parasitol 23: 309-314.

Maki J, Yanigasawa T 1980. A comparison of the sites of acid phosphatase activity in an adult filaria Stetaria sp. and in some gastrointestinal nematodes. Parasitology 81: 603-608.

Martinez-Grueiro MM 2002. Acid phosphatase activity in excretion/secretion products from Heligmosomoides polygyrus adults: an indicator of the physiologycal status of the worms. Parasitol Res 88: 946-949.

Massoulié J, Pezzementi I, Bon S, Krecji E, Vallete FM 1993. Molecular and cellular biology of cholinesterases. Prog Neurobiol 41: 31-91.

Moulay L, Robert-Gero M 1995. Leishmania donovani: enhanced expression of soluble acid phosphatase in the presence of sinefungin, an antiparasitic agent. Exp Parasitol 80: 8-14.

Peterson GL 1983. Determination of total protein. Methods Enzimol 91: 95-119.

Rathaur S, Robertson BD, Selkirk ME, Maizels RM 1987. Secretory acetylcholinesterases from Brugia malayi adult and microfilarial parasites. Mol Biochem Parasitol 26: 257-265.

Rhoads ML 1981. Cholinesterase in the parasitic nematode Stephanurus dentatus. Characterization and sex dependence of a secretory cholinesterase. J Biochem 256: 9316-23.

Sanderson BE, Ogilvie BM 1971. A study of acetylcholinesterase throughout the life cycle of Nipppostrongylus brasiliensis. Parasitology 62: 367-373.

Sharpe MJ, Lee DL 1981. Changes in the level of acetylcholineterase of Naematospiroides dubius and Trichostrongylus colubriformis following paralysis by levamisole in vitro. Mol Biochem Parasitol 3: 57-60.

Selkirk ME, Henson SM, Rusell WS, Hussein AS 2001. Acetylcholinesterase secretion by nematodes. In MW Kennedy, W Harnett (eds), Parasitic Nematodes, CAB International, 
London, p. 211-228.

Sutherland IA 1987. Anthelmintic Resistance in Nematodes, $\mathrm{PhD}$ Thesis, University of Leed, England.

Sutherland IA, Lee DL 1993. Acetylcholinesterase in infectivestage larvae of Haemonchus contortus, Ostertagia circumcincta, and Trichostrongylus colubriformis resistant and susceptible to benzimidazole anthelmintics. Parasitology 107: 553-557.

Tarrab-Hazdai R, Levi- Schaffer F, Gonzales G, Arnon R 1984. Acetylcholinesterase of Schistosoma mansoni. Molecular forms of the solubilized enzyme. Biochim Biophys Acta 790: 61-69. 